أثر عمارة رياض الأطفال على تحقيق التنمية الثاملة للطفل

\title{
IMPACT OF THE KINDERGARTEN'S ARCHITECTURE ON THE PERFORMANCE AND THE COMPREHENSIVE DEVELOPMENT OF THE CHILD
}

\author{
دكتور/ إسماعيل عبد الحكم صالح الثيمي \\ المعهد العالي للهندسة بمدينة 15 مايو ـ القاهرة
}

\section{Abstract}

(Received April 14, 2012 Accepted May 28, 2012)

The paper discusses the design process of the kindergarten. Perceiving its importance and designing it according to true scientific basics, which reflects and enhancing the sensory, aesthetic, and cultural level of the Egyptian child.

The research challenges also the importance of the childhood era, and the need to provide the sufficient necessaries of the child, whether they are environmental, social, cultural, educational, or recreational, which can be achieved throughout the kindergarten phase, the research discusses also the urge of dealing with the kindergarten as an entity that affects and is affected by its content and context.

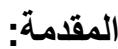

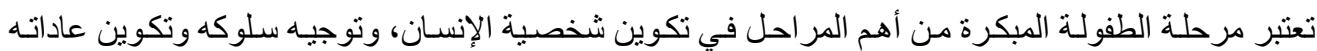

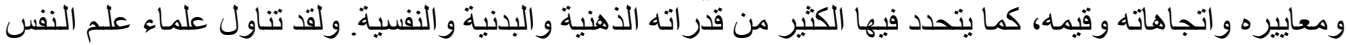

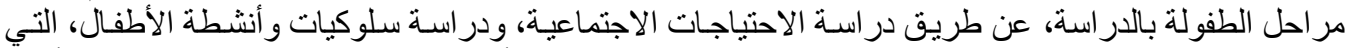

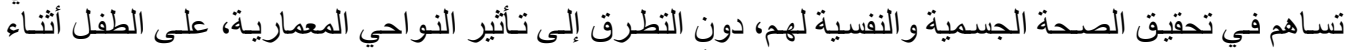

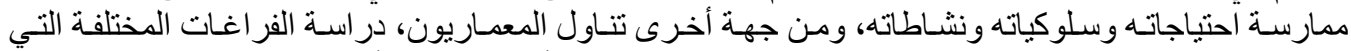

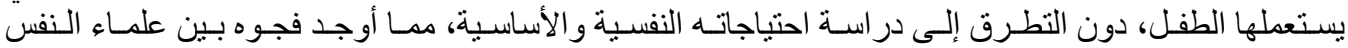
و المعماريين في توجيه وتقويم سلوك الطفل في البيئة العمر انية الموجيه النفود فيها.

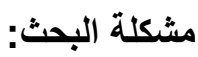

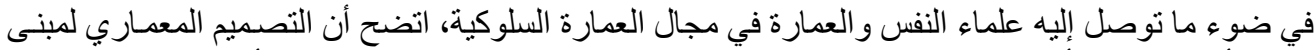

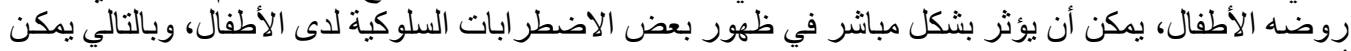

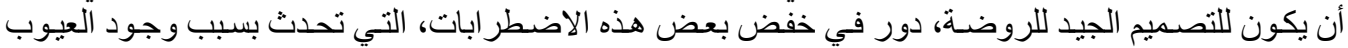

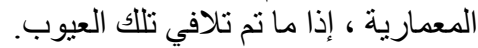

هدف البحث:

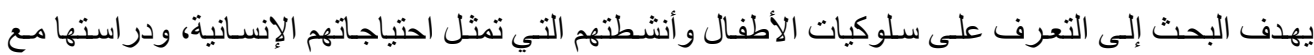

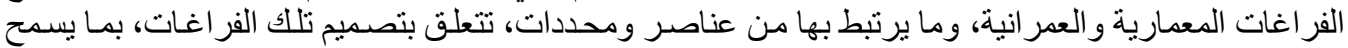

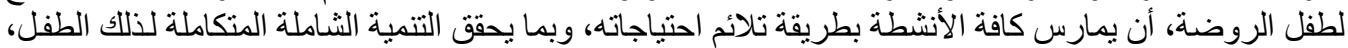
في المجالات (العقلية و الجسمية، وانية الحركية و الانفعالية، و الاجتماعية). 
منهجية البحث: - 20 - 20

استخدم البحث المنهج النظري، و الدنهج العملي التطبيقي.

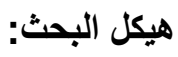

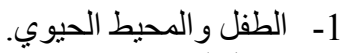

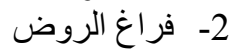

3- 2- ضوابط العملية التصميمية.

4- - الدراسة التطبيقية الميدانية

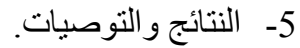

\section{1- الطفل والمحيط الحيوي}

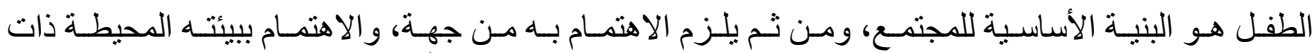

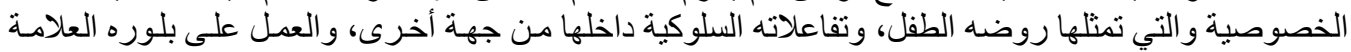
التبادلية بين الطفل، وبين محيطه المادي وغير المادي، بهدف توفير اليبئة المناسبة لنمو وتطور الطفل بشكل سليه.

$$
\text { 1-1 /حتياجات الطفل وانعكاسها على التصميه: }
$$

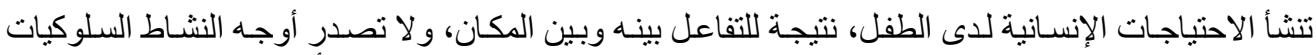

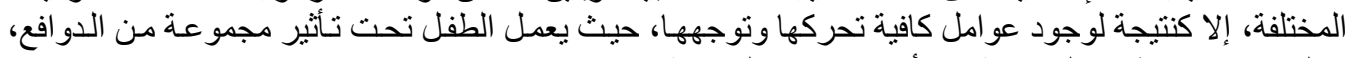
يتعلق بعضها بوظائفه العضوية، و الأخر بحاجاته المعنوية.

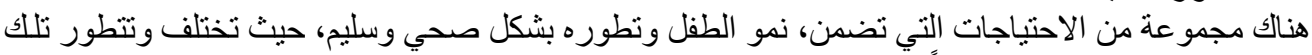

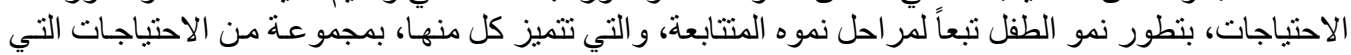

$$
\text { 1-1-1 تطور احتياجات الطفل: }
$$

تناسبها.

1-1-1 العو امل المؤثرة في خصائص واحتياجات النمو في الطفولة المبكرة، وتلك العو امل هي:

$$
\text { • • الجهاز البئة العصبي و الغدد. }
$$

1-1-1 3 اللعب و الترويح في حياة الطفل:[13]

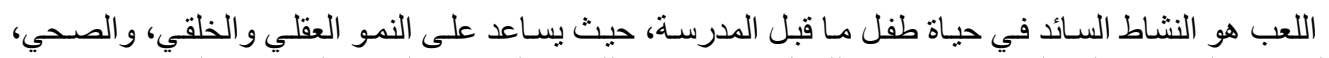

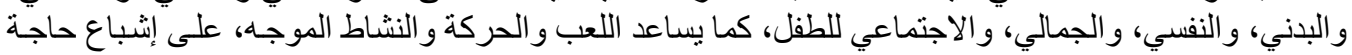

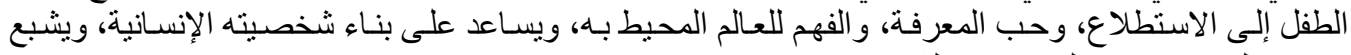

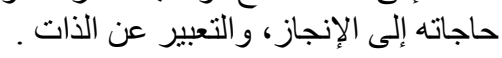

1-3-1-1 أهمية اللعب: تتعدد جو انب أهمية اللعب، وتأثيره على حياة الطفل وتطور ها، كما يلي:

$$
\begin{aligned}
& \text { • اللعب و التطور الجسدي الحركي. } \\
& \text { • اللعب و التطور الاجتماعي. } \\
& \text { • اللعب والتطور المعرفي (الإدر اكي). }
\end{aligned}
$$

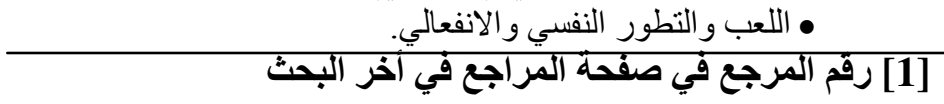

2-3-1-1 أنواع اللعب: تتتوع الألعاب تبعاً للمر احل العمرية للطفل بما يتناسب مع احتياجاته وقدر اته، كما يلي: 


\section{• (الألعاب التمثيلية (الإبداعية).

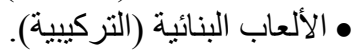

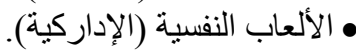

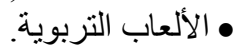

[2]: Kindergarten 2-1

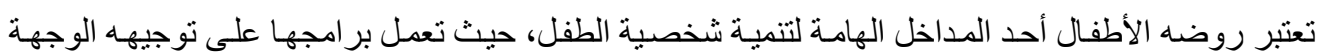

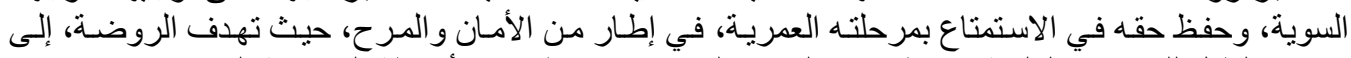

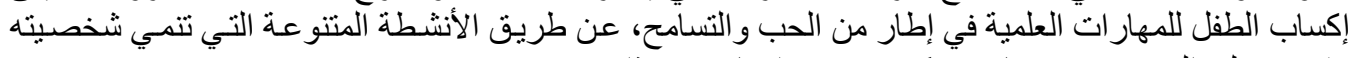
وقدرته على التعبير عن رغباته، وتكوين مفهوم إيجابي عن ذاتها. 1-2-1 فلسفة رياض الأطفال:

تشتنمل فلسفة رياض الأطفال على مجمو عة من الركائز (النفسية والتربوية، و الاجتماعية، و التعليمية، و الفكرية،

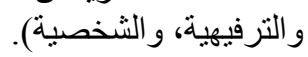

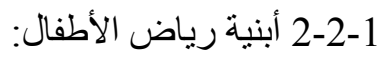

تمثل تهيئة البيئة الماديـة والنفسية في رياض الاضهل الأطفال أحد المتطلبات الأساسية اللازمة لتحقيق النمو الثـامل للطفل. 1-2-2-1 تصميم أبنية رياض الأطفال، وتجهيز اتها: ويشمل ذلك مجمو عة من العناصر مثل:

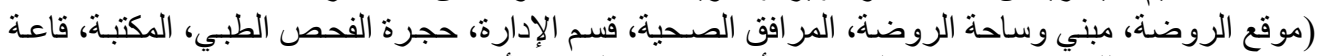
الكمبيوتر، ساحات اللعب وتجهيز اتها، الحديقة، الأثاث، غرف النشأ النشاط وأركانها).

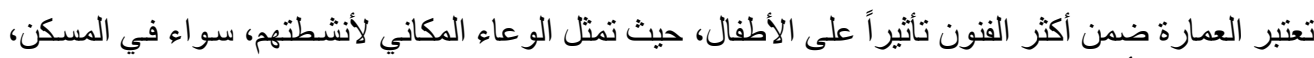

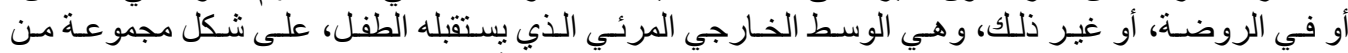

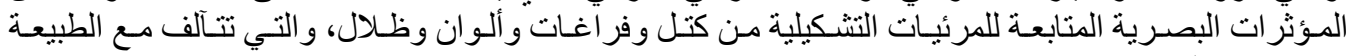

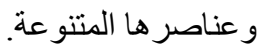

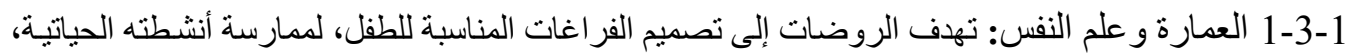

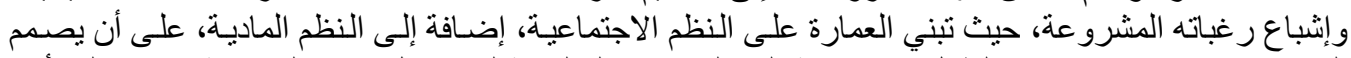

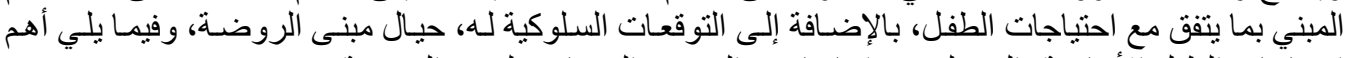
احتياجات الطفل الأساسية، التي بلزم مر اعاتها عند التصميم المعماري لمبني الروضة.

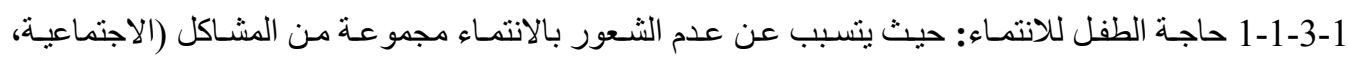

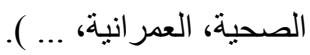

اللاحسي 2-1-3 حاجة الطفل للإحساس بالر احـة، حيث يتوفر الإحساس بالر احة عن طريق العامل الحسي، والعامل

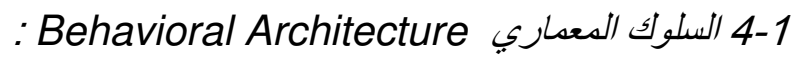

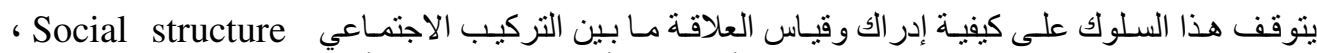

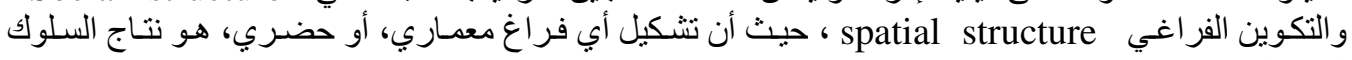

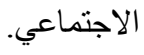

1-1-1 الأخطاء التصميمية و السلوك: يجب على المعماري أثناء العملية التصميمية، مر اعاة سلوك مستخدمي الفر اغ، حيث يمكن حدوث بعض الأخطاء التصميمية كما يلي: 


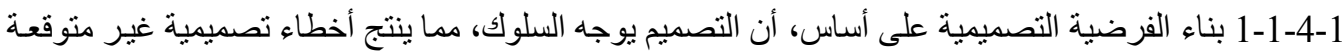
عندما يتبدل المفهوم التصميمي. 2-1-4-1 عدم در اسة تأثثير الأفكار التصميمية الإبداعية، على سلوكيات و أذو اق المستخدمين. 3-1-4-1-1 عدم الاهتمام بدر اسة التأثثر المتبادل بين السلوك والكو العمارة.

[4]:5-1 رياض الأطفال والتكوبن النفسي للطفل

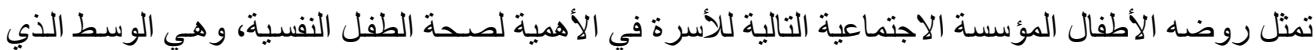

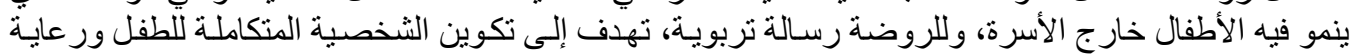
نموه البدني، و الذهني، والوجداني، والانيرة ولاجنماعي، في آن و احد. 1-6 تحقيق الثخصبة السوية للطفل:

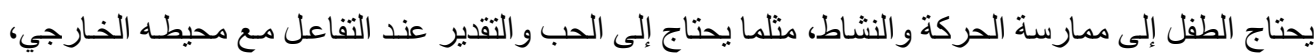

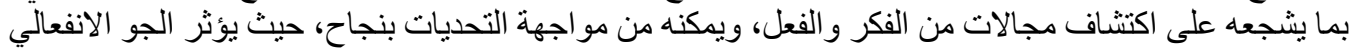

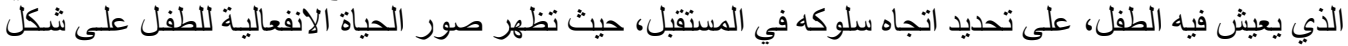

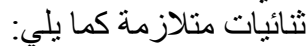

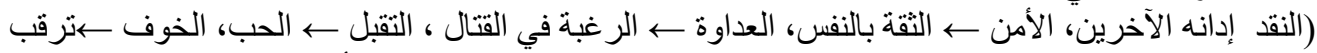

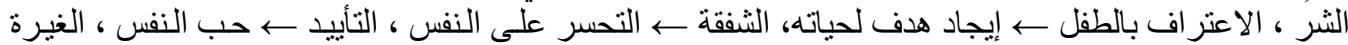

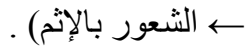
7-1 نظريات التعلم الخاصة بطفل الروضة، تنتوع هذه النظريات كما يلي: 7-7-1 نظرية التفتح الطبيعي للطفل (نظرية فريدريك فرويل).

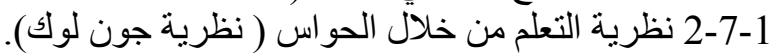

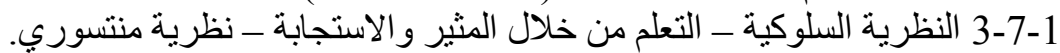

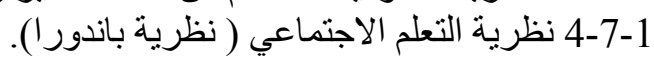
5-7-1 التعلم البنائي (نظرية بياجيه).

: Ecological orientation 8-1 التوجه البيئي

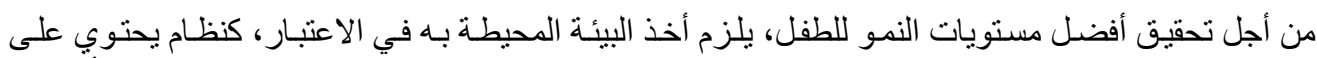

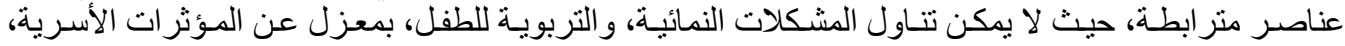

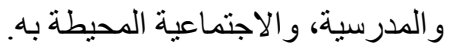

19-9 الرعاية التربوية في غرفة الدراسة:[5

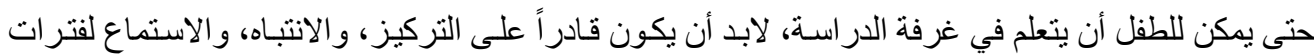

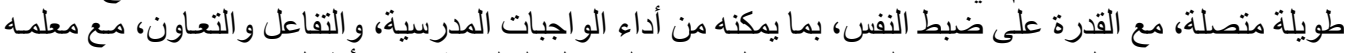
وزملاءه، وييين جدول رقم (1) دور العمارة في حل بعض المشاكل السلة السلوكية عند الأطفال. 
IMPACT OF THE KINDERGARTEN'S ARCHITECTURE ... 1841

جدول رقم (1) كيفية حل بعض المشاكل السلوكية للأطفال بالعمارة

\begin{tabular}{|c|c|c|}
\hline أسبريا معناريا & 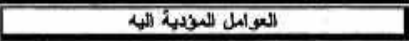 & الاضظطل اب \\
\hline 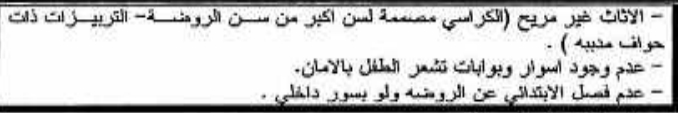 & 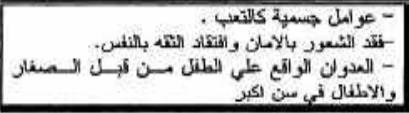 & العقولن \\
\hline 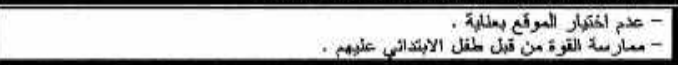 & 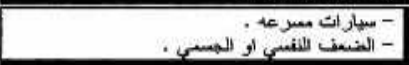 & الدكف \\
\hline 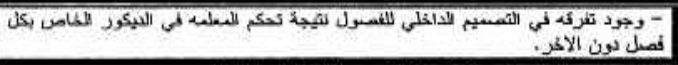 & 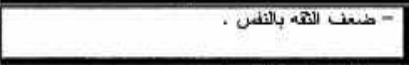 & الغرئ \\
\hline 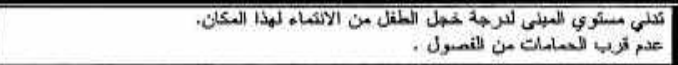 & 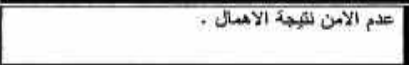 & (الإنطو امو الخجلل) \\
\hline 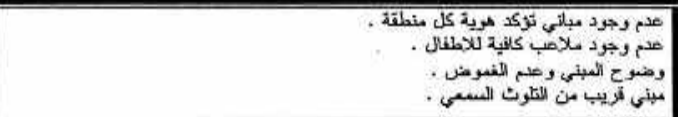 & 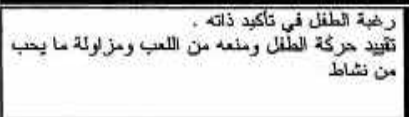 & العيد \\
\hline 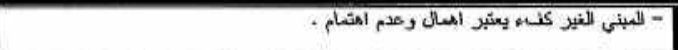 & 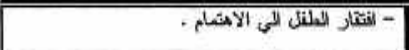 & توبيات الفضشب \\
\hline 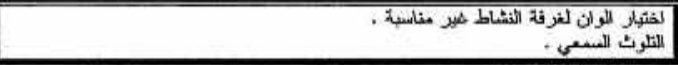 & 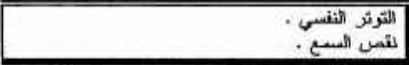 & الفيطراب الكلام \\
\hline 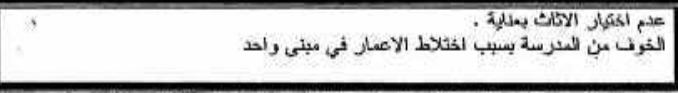 & 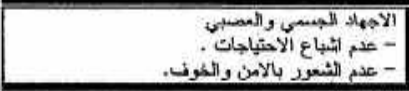 & افر ابات النوم \\
\hline 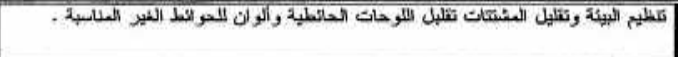 & - Cy+ & نكص الإتباه \\
\hline 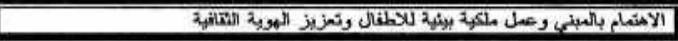 & 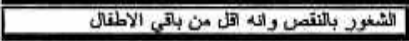 & 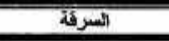 \\
\hline 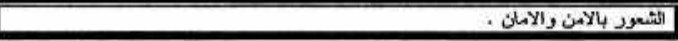 & 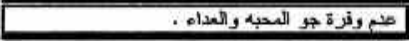 & (الكأب \\
\hline 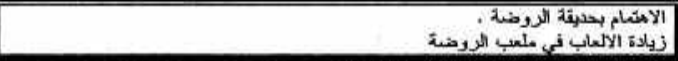 & 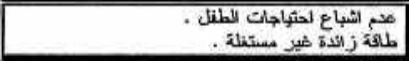 & 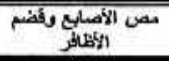 \\
\hline 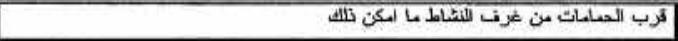 & 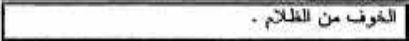 & المتبول الذلاد الدي \\
\hline
\end{tabular}

10-1 النشأة الاستقلولبة للطفل:

يمكن إكساب الطفل السلوك الاستقلالي غير الاعتمـادي، من خـالال تمكينه من اكتشـاف البيئة التي يعش فيها،

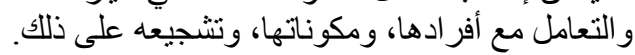

ويوضح جدول رقم (2) الاعتبار ات السلوكية الصحيحة، و وعناصن التهر التصميم المقابلة لها.

جدول رقم (2) الاعتبارات السلوكية الصحيحة، وعناصر التصميم المقابلة

\begin{tabular}{|c|c|}
\hline عناصر التصميم المقابلة & الاعتبارات السلوكية الصحيحة \\
\hline تصميم سـل و غير معقد. & البساطة و المرونة في التعامل مع الأطفال \\
\hline عناصر التصميم و اضحة عن طريق الأجزاء و اللون. & الوضوح في كل ما يقال أو يتم عمله \\
\hline تصميم متعدد في أهدافه التعليمية و الترفيهية. & الاحتر ام للر أبي و الفكر. \\
\hline و البرتقالي. الألوان المبهجة يعطي الشعور بالتفاؤل مثل اللون الأخضر & التفاؤل و المثابرة في العمل. \\
\hline تصميم محدد المعالم. & الثقة في النفس و الغير \\
\hline من ذات البيئة. & ي التفاعل و الأحاسيس \\
\hline
\end{tabular}

11-1 فلسفة تصديم مبني الروضة:

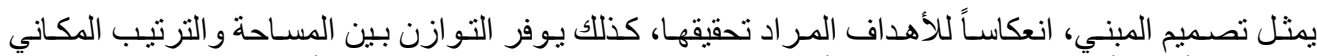

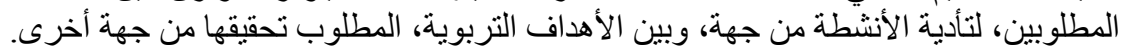


وفيما يلي بعض الفلسفات التصميمية لمبني الروضة:

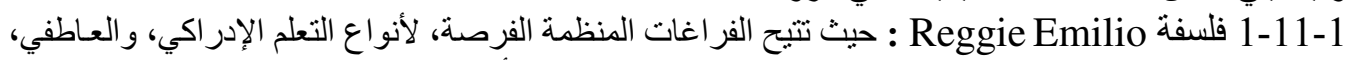
و الاجتماعي، ويتم ذلك من خلال مجمو عات تسمح بالمشـاركة، في الأنثطة، والاتصـال، و التعاون، و الصر العراع،

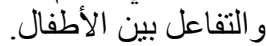

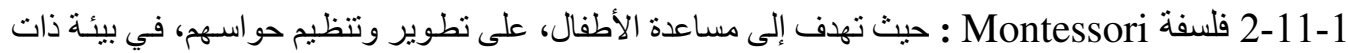
أنشطة عملية، يشارك فيها الأطفال بالملاحظة وتقليد الكبار.

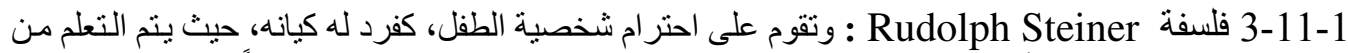

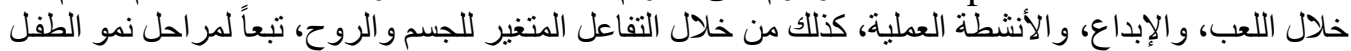

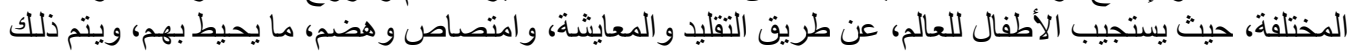
من خلال خلق بيئة لعب آمنة وجذابة.

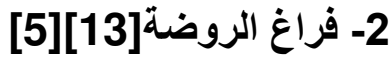

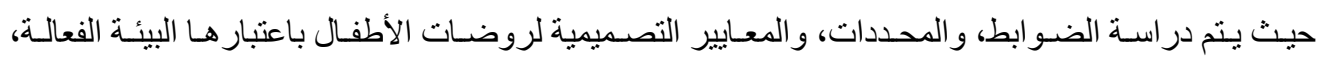

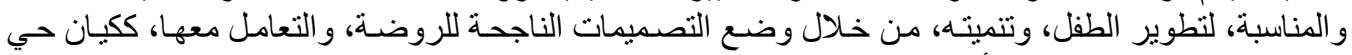
ديناميكي، يؤثر في الطفل، وينأثر بوجئه دود الطفل في نطاقه.

1-2 أهمية الروضة لتندية وتطور الطفل:16]

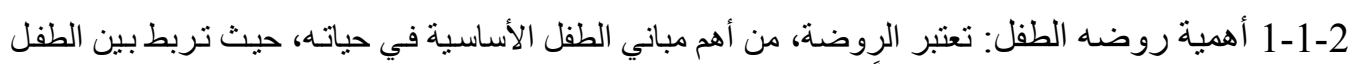

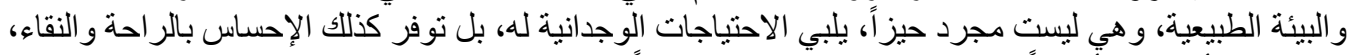

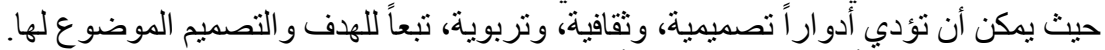

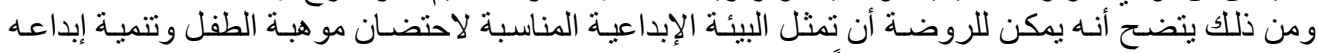

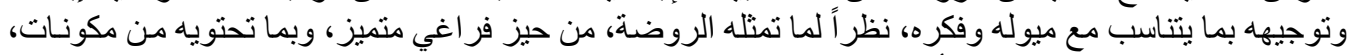

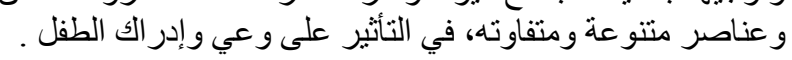

2-1-2 نأثثر الخصائص الفيزيائية للفر اغ على سلوكيات الطفل: يؤثر شكل وارتفاع الفراغ، في توجيه طبائع الطفل، ويسهم سلباً أو إيجاباً، في تطور مفاهيمه الفر اغية.

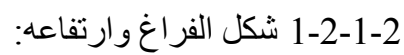

يتسبب الفر اغ المربع المسقط في إهدار المساحة المركزية ، كما تشجع الغرف شديدة الاستطالة، على الألى الأنشطة

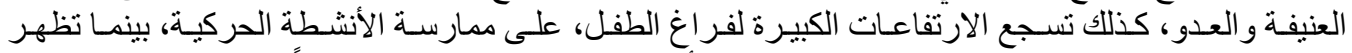

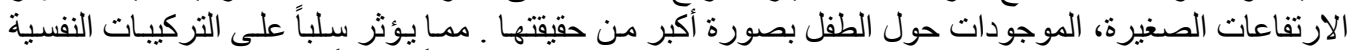

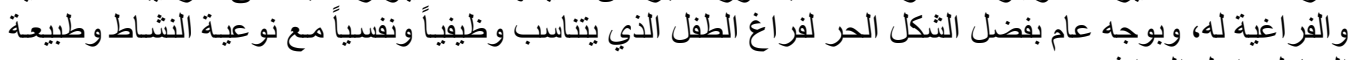
التعامل داخل الفراغ.

2-2-1-2 اللون: يؤثر اللون، على الطبيعية النفسية والإدر اكية عند الطفل .

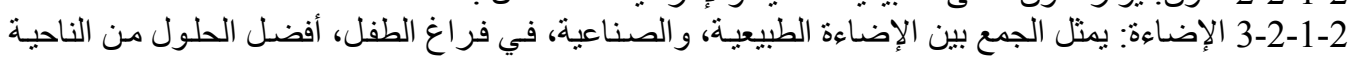

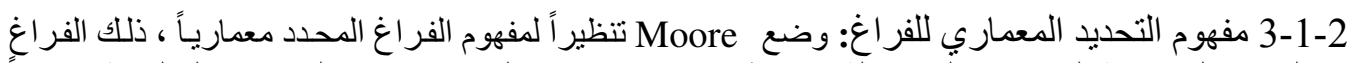

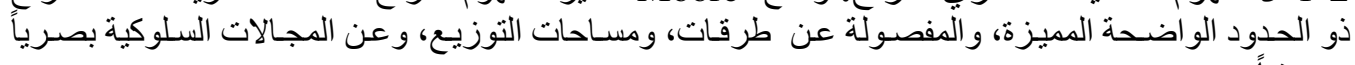
وصوتياً.

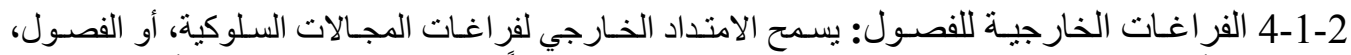

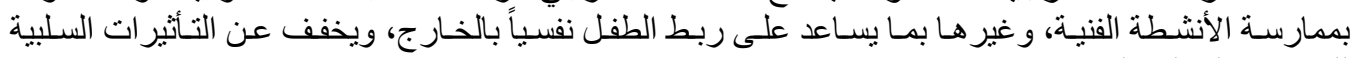
للفر اغات المقفلة عليه. 
: open plan classroom 5-1-2 فكر المسقط المفتوح للفصل

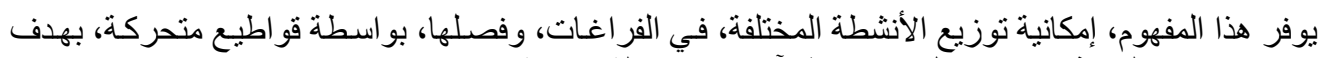
تمكين مستخدمي الفراغ، من الانتقال من نشاط لآخر في سهولة ولنة وحرية.

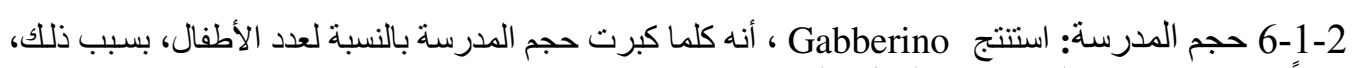
نو عاً من عدم الارتباط النفسي، بين الطفل و المدرسة. 7-1-2 العو امل المناخية ومستوي أداء الطفل:

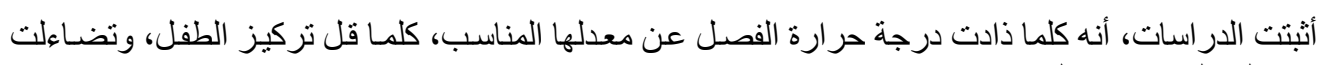

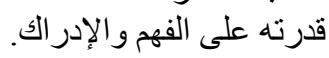

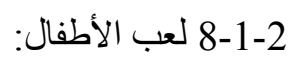

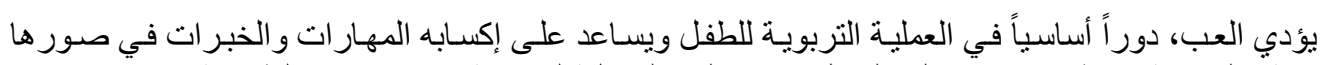

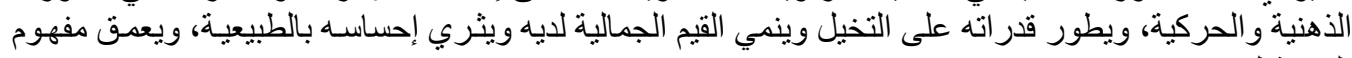

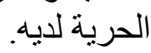

9-1-2 - 9-1 الفر اغات الخارجية للحضانة:

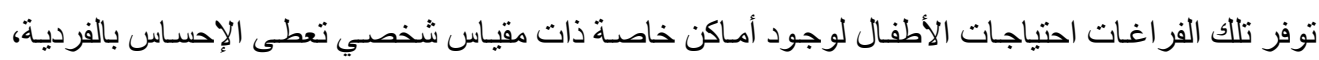
و التو اصل مع عناصر البيئة الطبيعية. 2-2 تأثير التصميم على الطفل:

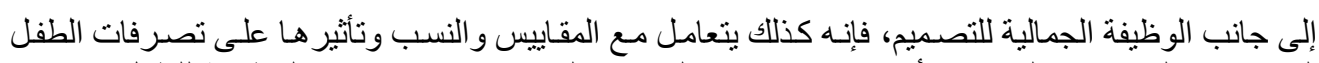

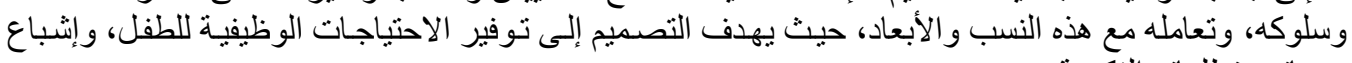
رغباته وتطلعاته الفكرية.

\section{3- ضوابط العملية التصميمية}

1-3 المحددات التصميبية لروضات الأطفال:311][12]

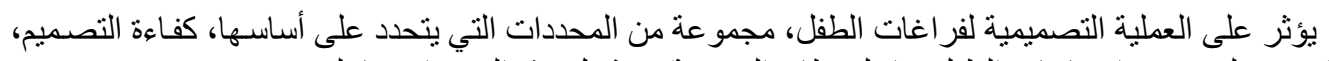

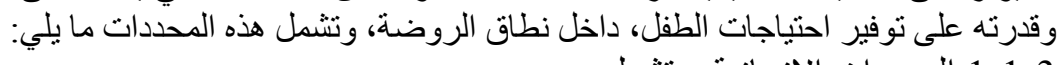
1-1-3 المحددات الإنسانية: وتنشمل:

$$
\begin{aligned}
& \text { • • أبعاد ومقياس الطفل. } \\
& \text { • احتياجات الطفل ومتطلباته. } \\
& \text { المحددات الاجتماعية. } \\
& \text { 2-1-3 المحددات البيئة: وتشمل: } \\
& \text { • خ خوامل المناخ. الموقع. } \\
& \text { 3-1-3 المحددات الجمالية. } \\
& \text { 4-1-3 المحددات الوظيفية. }
\end{aligned}
$$


5-1-3 المحددات الاقتصادية وتشمل:

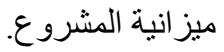

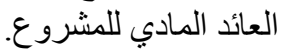

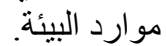

6-1-3 - - 6 المحددات التكنولوجية.

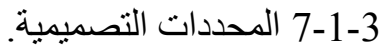

2-3 الأسس والدعايير التصديمية لروضات الأطفال:

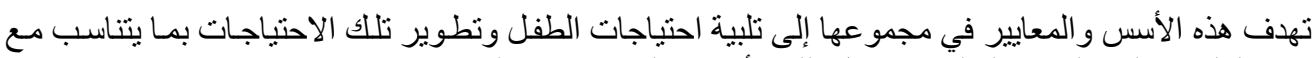

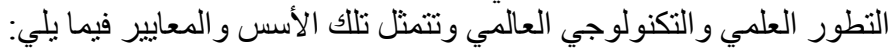

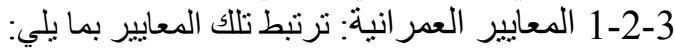

طبوغر افية الموقع (كنتور الأرض العن والمناسب الطبيعية للموقع) شكل رقم (1).

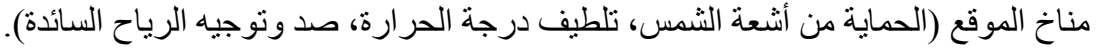

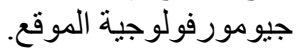

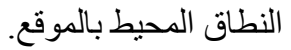

2-2-3 المعايير المرتبطة بالفكر التصميمي: وتتمل:

المبادئ العامة الموجهه لتصميم روضة الطفل (المقياس، الانتظام، الوحدة، السيطرة، التكر ار و الايقاع ،

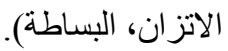
المبادئ المرتبطة بتصميم بيئة الطفل (الاستمر ارية، التتوع الفر اغي، المرونة، التفرد)، شكل رقم (2)

[10] 3-2-3 المعايير الوظيفية: وتشمل

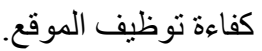
تحقيق المعدلات القياسية. التوظيف الناجح لعناصر ومكونات الفئات الفراغ ( البعد الحركي، البعض النفسي، البعد الذهني، البعد البيئي ، (البعد الاجتماعي)، شكل رقم (3). 4-2-3 المعايير الاقتصادية: وتشمل:

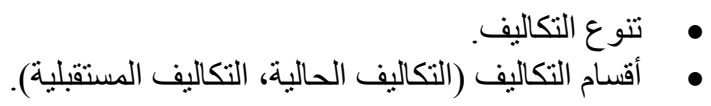
5-2-3 المعايير الإدر اكية: وتنثمل:

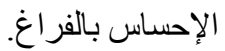

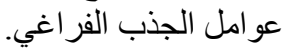

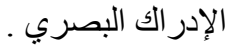

6-2-3 المعايير النفسية: وتتثمل:37

المعايير الأمنيـة ( توفير الحمايـة والأمسن ، تـوفير المدخل الآمـن، وحمايـة الفراغـات ، الحفـاظ على

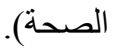
المعـيير الجماليـة ( توظف العلامـات المميزة، تحقيق الأضـواء، تحقيـق الإيحـاء البصـري، عناصر

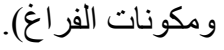




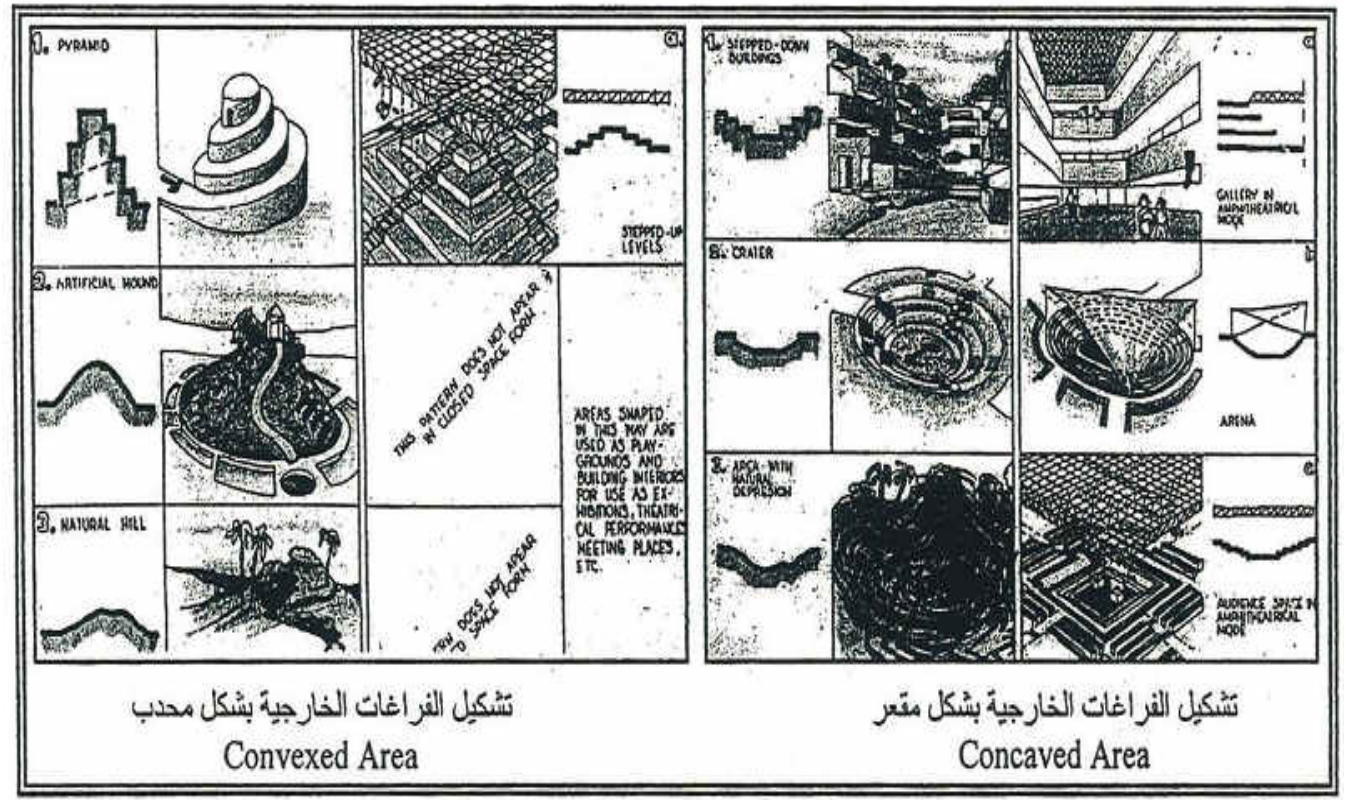

شكل رقم (1) استغلال كنتور الموقع في تشكيل بيئة الطفل بما يحقق له الحافز لإثارة الملكات و الإبداعات الخاصة

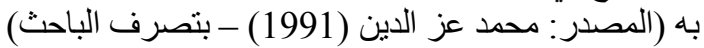

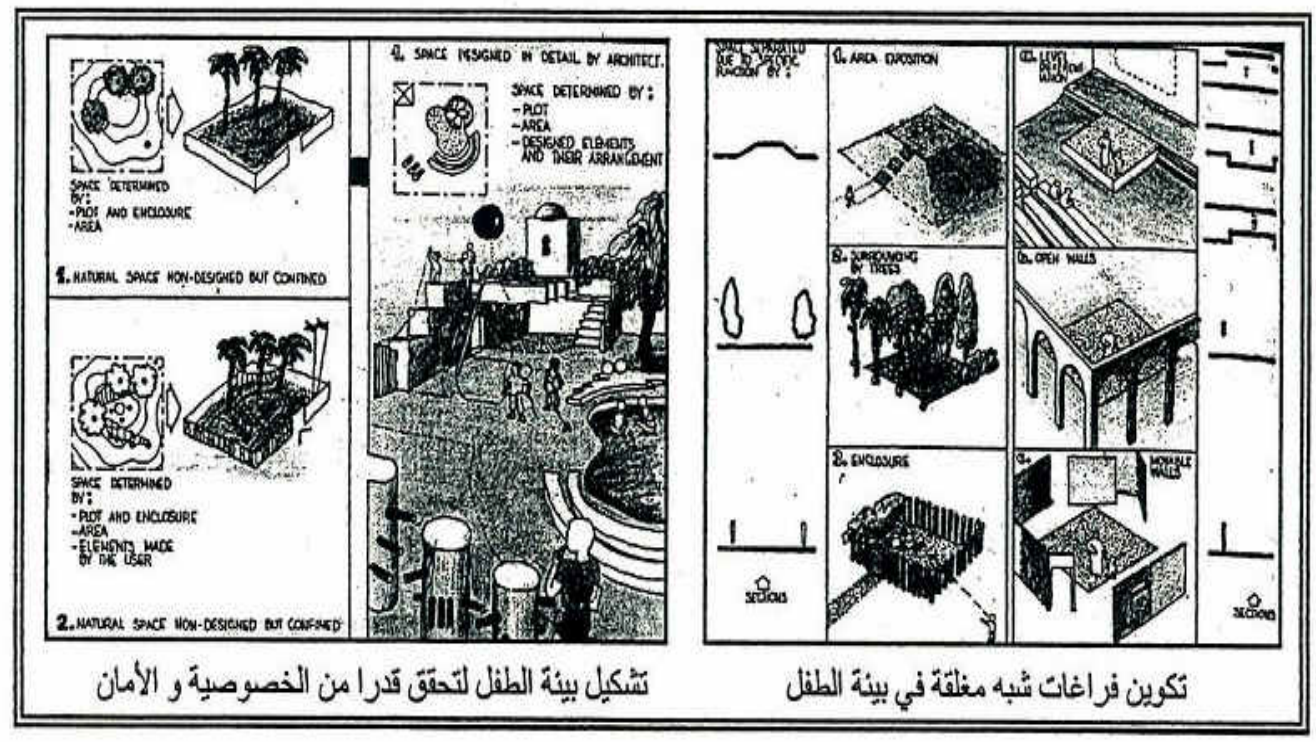

شكل رقم (2) أنماط العزل للفر اغات المخصصة للأطفال (المصدر : د/ محمد عز الدين 1991 ،

$$
\text { بتصرف الباحث) }
$$




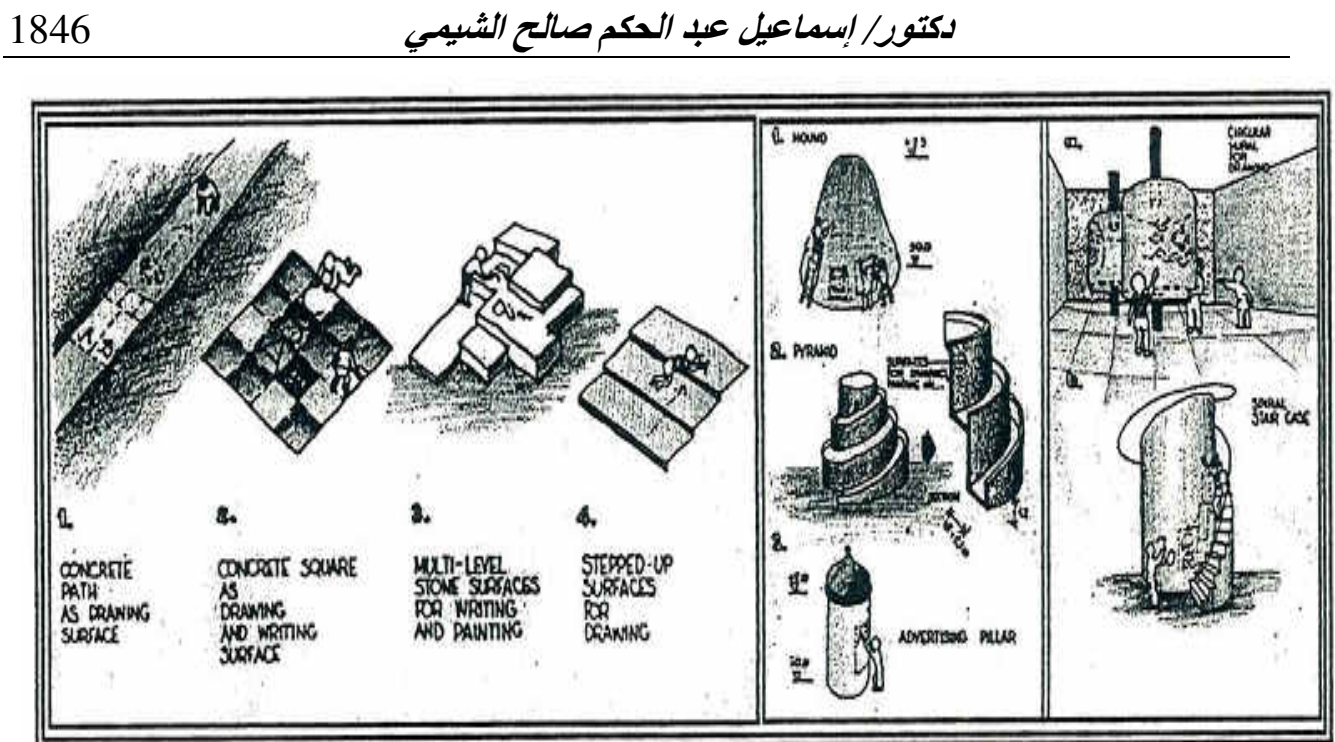

شكل رقم (3) نماذج للنشاطات التي تنمي المهار ات الاجتماعية للطفل (المصدر : د. محمد عز الدين 1991 ،

$$
\text { بتصرف الباحث) }
$$

\section{4- الاراسة الميدانية}

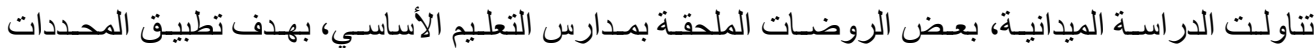

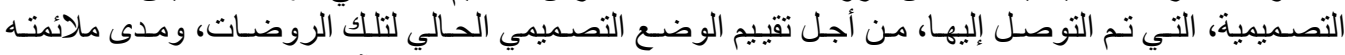

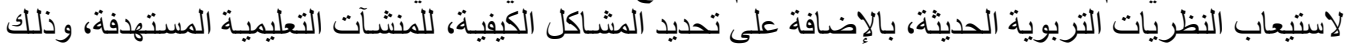

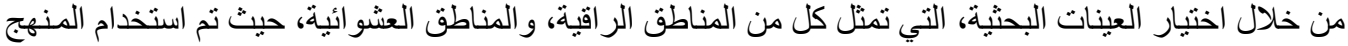
الاستقصائي من خلال الزيار الزيات التهات الميدانية.

$$
\begin{aligned}
& \text { 1-4 مدرسة الإمام علي الابتدائية المشتركة - الدقي ـ الجبزة ( كمثال للمناطق الراقية): } \\
& \text { • • المساحة عينة للروضة } 512 \text { م2 }
\end{aligned}
$$

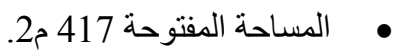

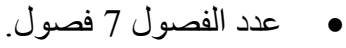

$$
\begin{aligned}
& \text { • كثافة الفصل } 52 \text { طفل / الفصل. }
\end{aligned}
$$

يوضح شكل رقم (4) منطقة الدقي ، شكل رقم (5) الموقع العام للعينة البحثية، جدول رقم (3) يوضح المعدلات التصميمية للعينة البحثية. 


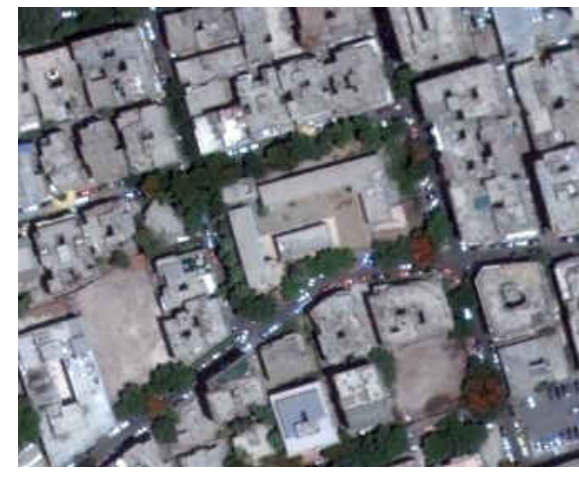

شكل رقم (5) الموقع العام للعبية البحثية

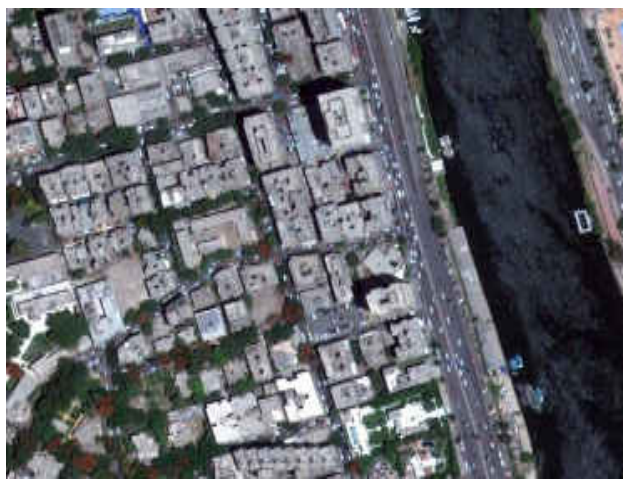

شكل رقم (4) منطقة الدقي

جدول رقم (3) المعدلات التصميمية للعينة الدراسية المصدر الباحث

\begin{tabular}{|c|c|c|c|c|}
\hline ملاحتات & تلمبدة مات التصمقى من & 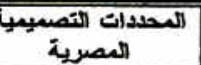 & الوضع القاتم & وجه المتارته \\
\hline 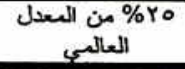 & 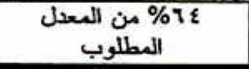 & $t^{3} I \sum 0 T$ & $r_{b} q r^{\prime}, \cdots$ & مساحة الموقع \\
\hline 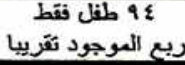 & اكثز من مرة ونصلب من المطلوب & r & Jerte & عدد الاطفل \\
\hline المحدد اللعالميى & 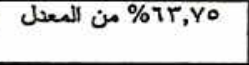 & $t^{5} \varepsilon, \ldots$ & $Y_{p} Y_{, 00}$ & تصبيب الطفل من مساحة الموفيع \\
\hline المحدد العالميى & \% \% من المعدل & $t^{b} T_{1} 0^{\circ}$ & $Y_{p} \mid, 10$ & 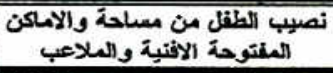 \\
\hline & 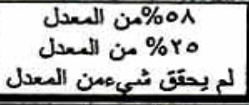 & 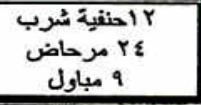 & 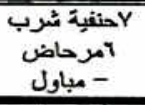 & تصيب الططل من دورات المباة \\
\hline 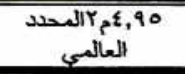 & \% \%ن بن المعدل & $t^{b} t, 0$. & $r^{3 *, Y}$ & 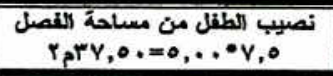 \\
\hline
\end{tabular}

A

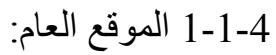

• المبني مكون من عدة أدوار، في حين أن الروضة العالمية، تشترط أن يكون من دور و واحد فقط.

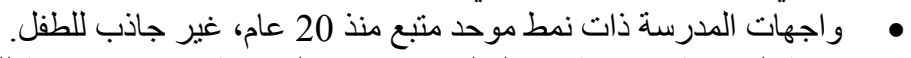

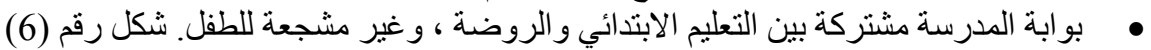

2-1-4 الفصول الدراسية: ما لم يتحقق طبقاً لمحددات التصميم:

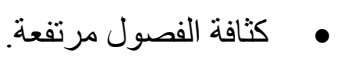

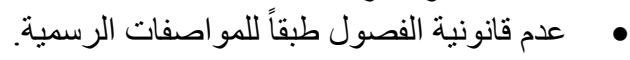

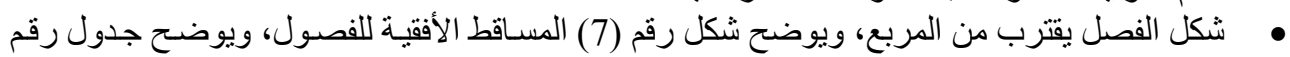

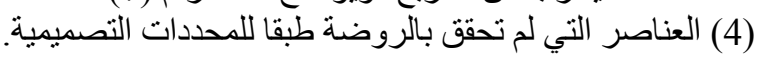



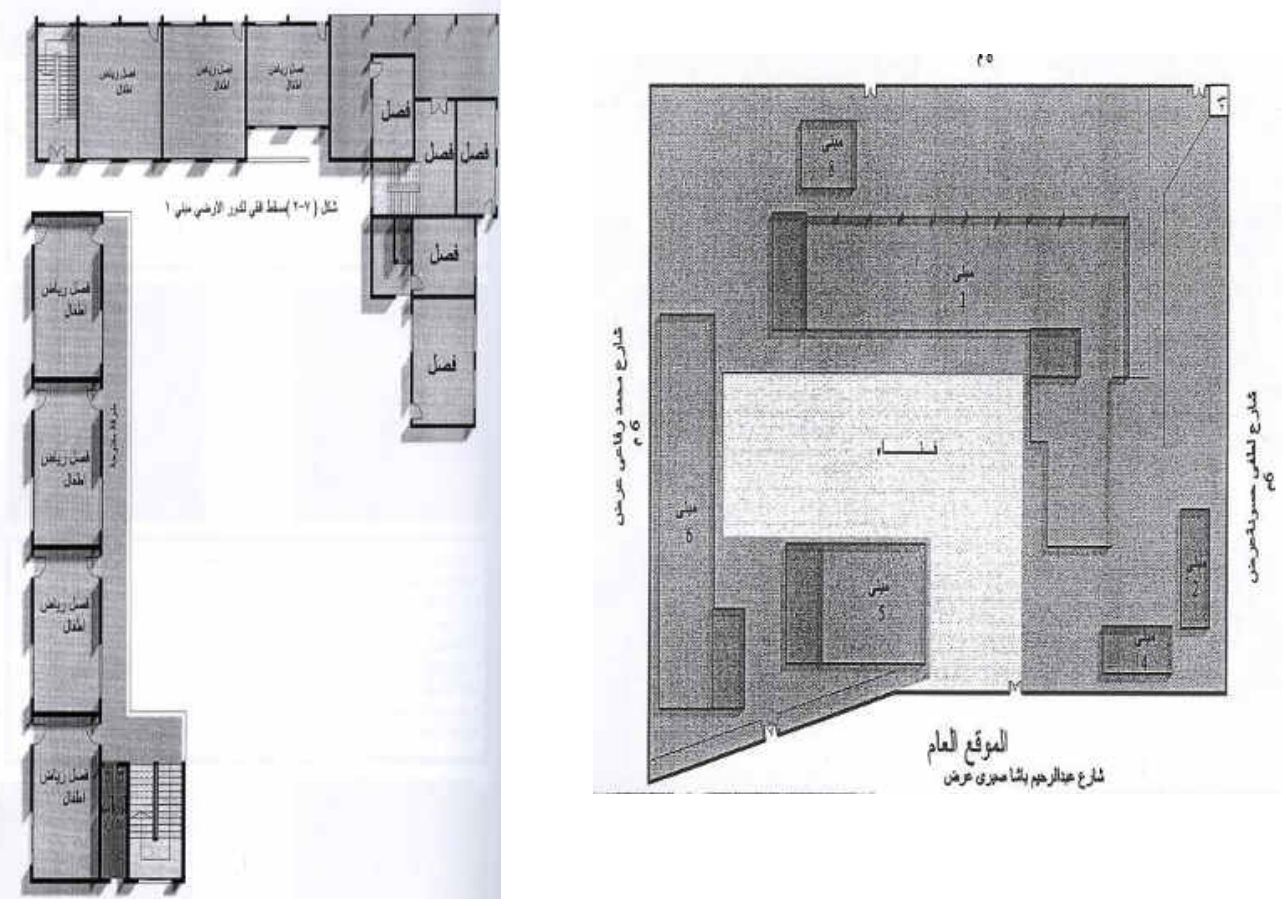

شكل رقم (7) المساقط الأفقية للفصول

شكل رقم (6) الموقع العام

جدول رقم (4) العناصر التي لم تتحقق بالروضة طبقا للمحددات التصميمية المصدر الباحث

مالم يتحتق طبقا المحددات :

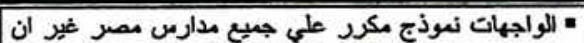

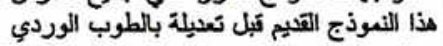

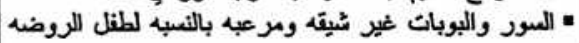
" المواجهات ليعت جميله ولا تذعوا الطقل اليى الآثارة

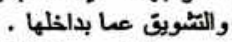
" حجم المبنى يبعث الخوف في نفس طفل الروضة

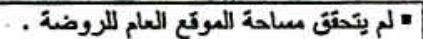

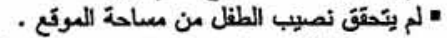

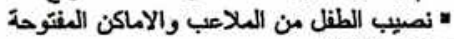

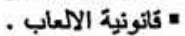

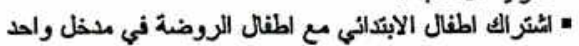

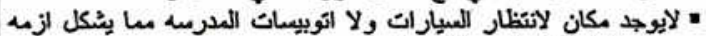

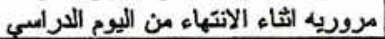

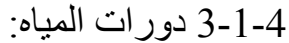

$$
\begin{aligned}
& \text { • عدد الدورات غير كافي. } \\
& \text { • بعد المسافة بين الحمامات و الفصول. } \\
& \text { 4-1-5 الملاعب و الأماكن المفتوحة: }
\end{aligned}
$$

•عدد الألعاب غير كافي، ويتسبب ذللك في حدوث التز احم، ويعرض الأطفال للخطر.

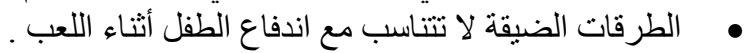

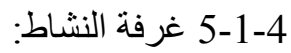
• رفة النشاط غير مرتبة ومشتته للعين. 


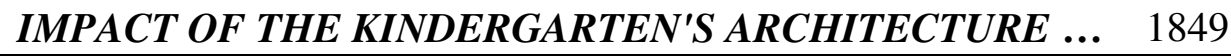

يوضح شكل رقم (8) إجمالي الملاحظات التي تتعلق بفر اغات الروضة .

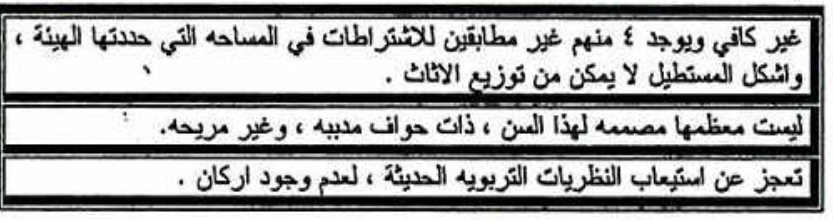
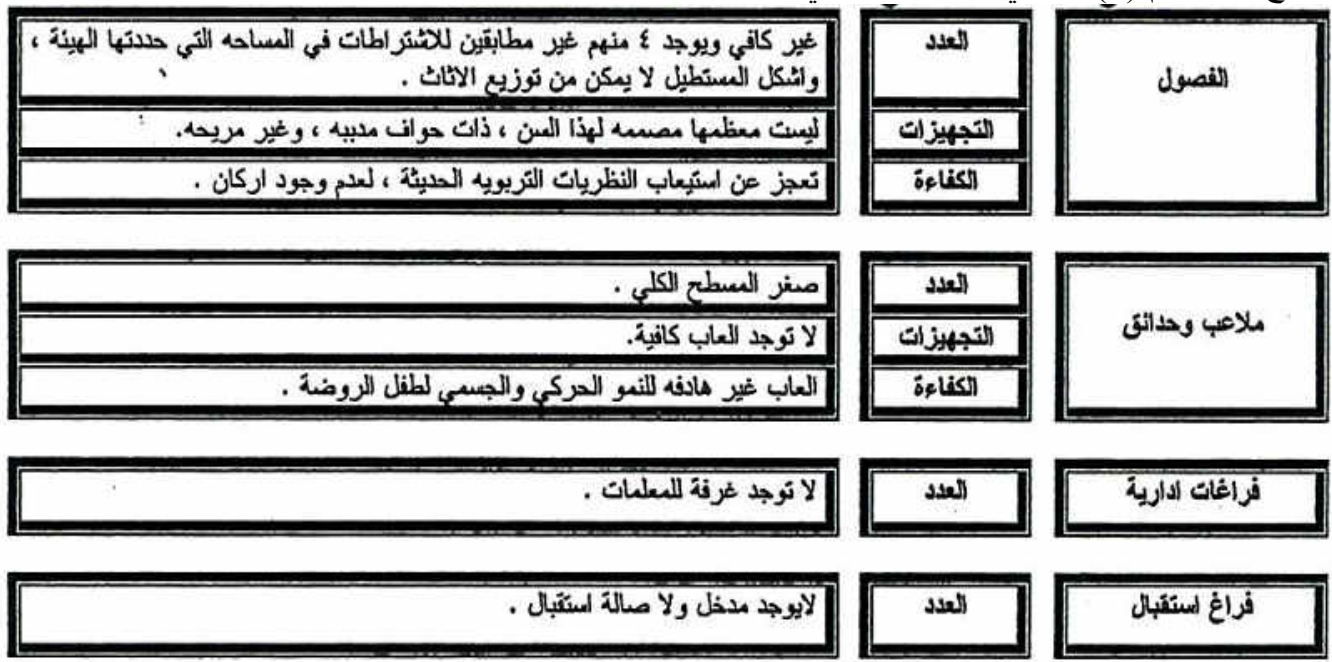

$$
\text { لا توجد غرنة اللثُّاط الحركي وبالتالي لا تستخفم في مجلس الاباء. }
$$
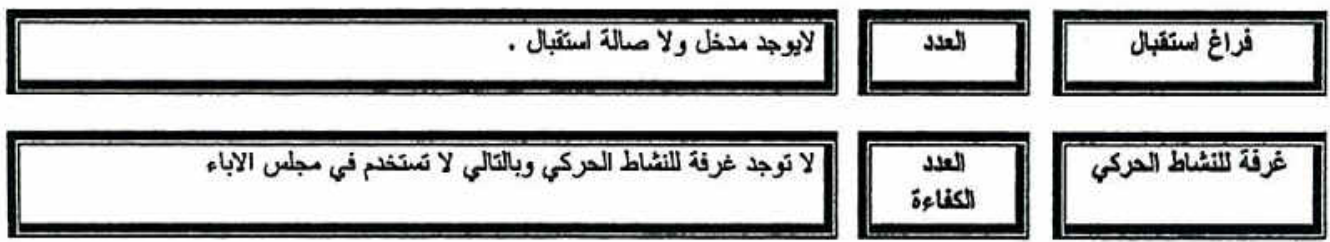

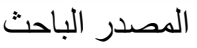

شكل رقم (8) إجمالي الملاحظات التي تتعلق بفر اغات الروضة

$$
\text { 2-5 مدرسة الحرية الابتدائية المشتركة ـ إمبابة - الجيزة (مثال للمناطق العشوائية): }
$$

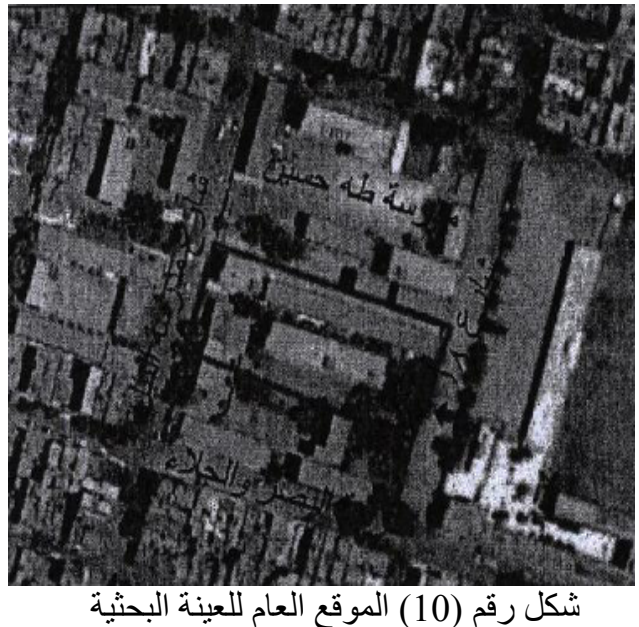

شكل رقم (10) الموقع العام للعينة البحثية

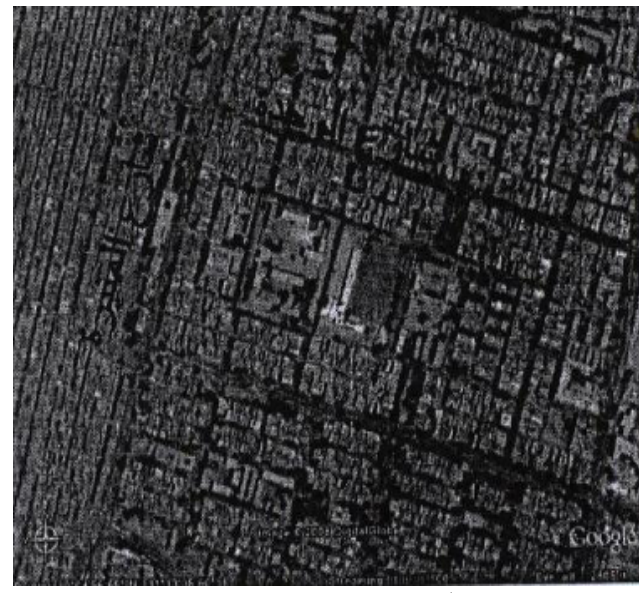

شكل رقم (9) منطقة إمبابة 
جدول رقم (5) المعدلات التصميمية للعينة البحثية .

\begin{tabular}{|c|c|c|c|c|}
\hline ملاحظات & 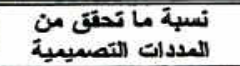 & المحدات التصمية & التوضع القاتم & وجه المقارته \\
\hline 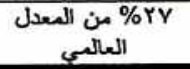 & 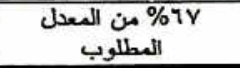 & $r_{p} \varepsilon r Y$ & $t_{b} t_{1 N A, T 0}$ & مساحةً الموقع \\
\hline 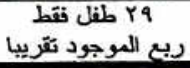 & اكتر المعل مرة المطلوب من من & debrr & (b) • 1 & عدد الاطفال \\
\hline 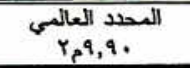 & & $t_{5} \varepsilon, \cdots$ & 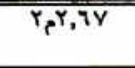 & نصيب الطفل من مساحة الموقع \\
\hline المحدد العالمى & 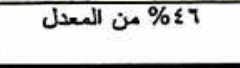 & $t^{5} t^{30 .}$ & $r^{8}, 10$ & 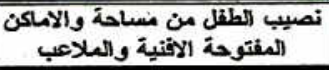 \\
\hline الحمامات وشُتركي & 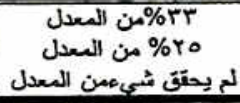 & 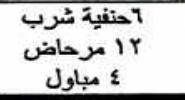 & كاحنفية شربرب - مباول & تصيب الطفل من دورات المياة \\
\hline 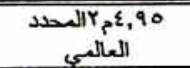 & 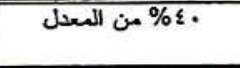 & $r_{p} T^{\prime} 0$. & $r^{6}, \ldots$ & 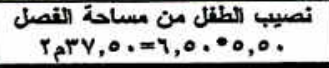 \\
\hline
\end{tabular}

1-2-4 الموقع العام: تم ملاحظة ما يلي:

• المبني مكون من دورين، في حين أن المعايير العالمية، تشترط أن يكون دور واحد فقط.

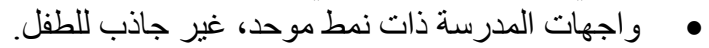

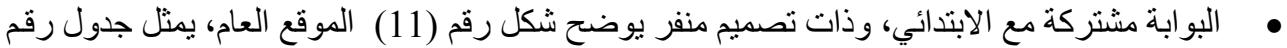

(6) العناصر التي لم تتحقق بالروضية، طبقا للمحددات التصميمية.

2-2-4 الفصول الدر اسية: ما لم يحقق طبقا لمحددات التصميمية:

$$
\text { • ألوان الفصل قاتمة. }
$$

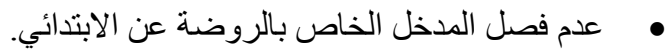

• • شكل الفصل لا بسمح بتغيير شكل الجلسات. يوضح شكل (12) المساقط الأفقية للفصول.

3-2-4 دورات المياه: ثم ملاحظ ما يلي:

• عدد الدورات غير كافي للأطفال.

• • • الحمامات مشتركة بين الأو لاد و البنات.

• • ارتفاع الأحو اض بالنسبة لطفل الروضة.

4-2-4 الملاعب و الأماكن المفتوحة:

• ل الوجد فر اغات للعب وإضافة لعدم توفر الألعاب، مما يسبب شعور الطفل بالاحباط، ومن ثم العزوف

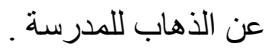

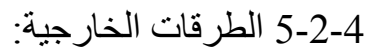

• • عروض الطرقات لا تتناسب مع اندفاع الأطفال.

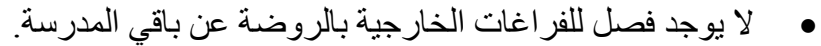

يوضح شكل رقم (13) إجمالي الملاحظات التي تتعلق بفر الرخات بات الروضة. 


\section{5- النتائج العامة}

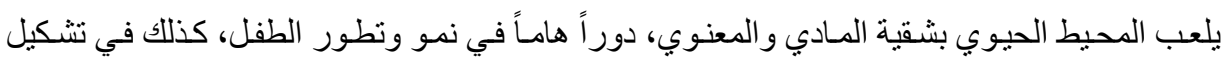

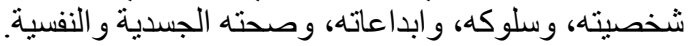

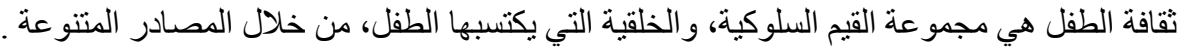

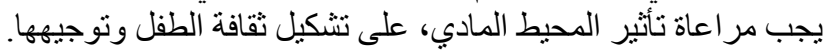
يوفر التصميم الناجح لروضة الأُطفال، البيئة المناسبة لتطوير، وتنية ولتمية الطفل، وتشكيل شخصية وطريقة تفكيره.

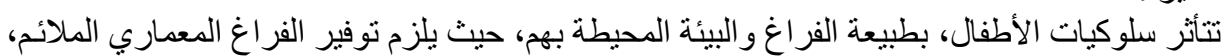

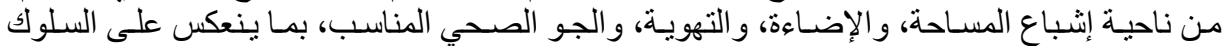
السوي للطفل.

يفضل الفصل المكاني بين الأطفال ذوب الأعمار المختلفة.

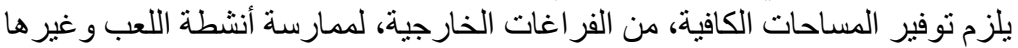

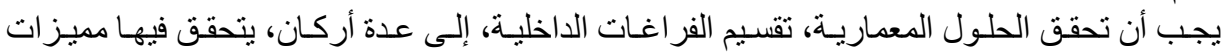

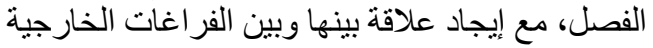

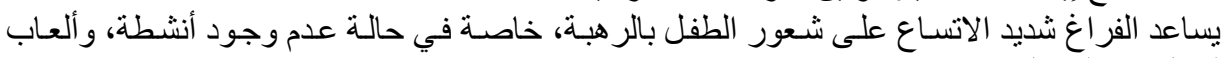
لشغل هذا الفراغ.

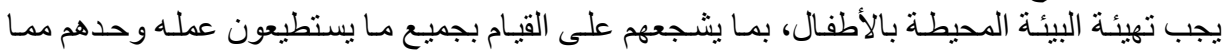

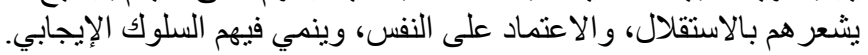

\section{6- التوصيات}

1. ضرورة نوفير الاندماج و التداخل، بين الطفل و الحيز الذي يتو اجد فيـه، بما يسـاعد على التفاعل، والتأثير

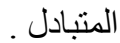

2. نشر الوعي لدي الطفل، يقيمـه البينـة الطبيعيـة بكافـة عناصـر ها، بهدف الحفاظ عليها، وحمايتها، وتغذيـة الانتماء إليها

3. يجب ألا تتعدي المسـافة بين الروضـة، ومكان إقامـة لطفل، عن 500م، في حالة إقامتها وسطوومنطقة سكنية. 4. اختيار الموقع الصحي للروضة وتوفير الاشتر اطات البيئة و الصحية المناسبة، إضـافة إلى توفير معايير السلامة والأمان لها.

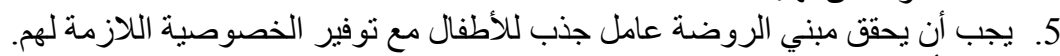

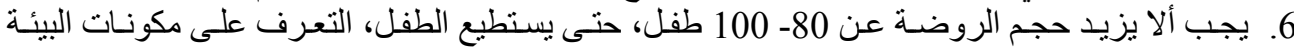

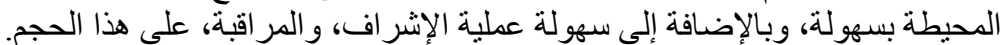

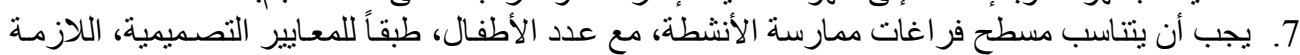

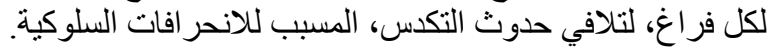

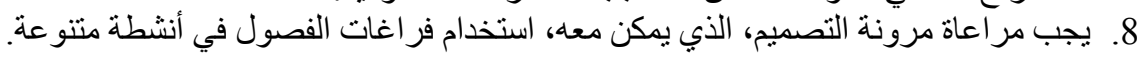

\section{Reference المراجع}

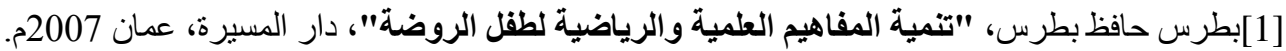

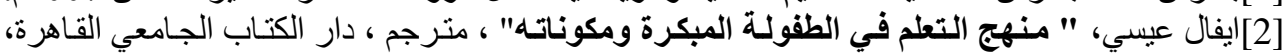
2005م.

[3]سامي محمد ملحم، "الأسس النفسية للنمو في الطقولـة المبكرة"، دار الفكر ، الطبعة الأولي القاهرة، 2007م.

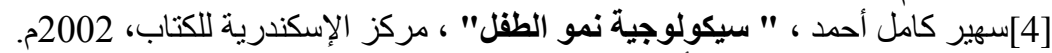

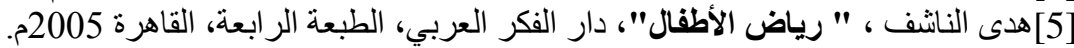

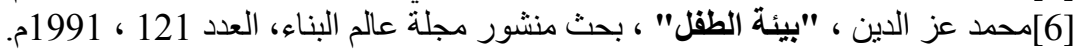


[7] أم هاشـ خلف مرسي، "الاضطر ابات السلوكية الثـائعة في ريـاض الأطفـال"، رسـالة ماجستير، كلية

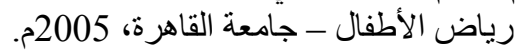

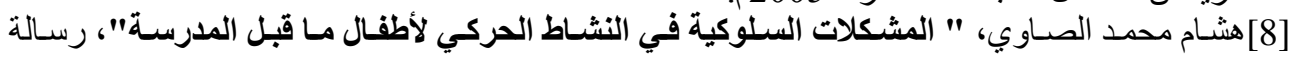

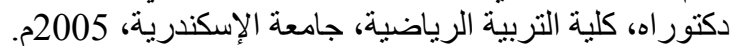

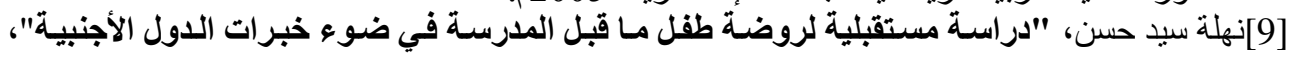

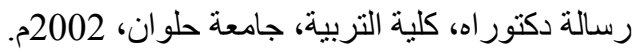

[10] Mark Dukek, "kindergarten Architecture", E.\& Fn. spon", first edition, 1996.

[11]Tipsuda patumanon, "Inside children's places A phenomenological study of social spatial worlds of thai" day care center 1989.

[12]Tony Cassiddy , " Environmental psychology behavior and experience in context", none college, northampton, 1997.

[13]Central mortage \& housing corporation, "play spaces for preschoolers", centre for arch and urban planning research, university of Wisconsin, Milwaukee, 1978. 